Indexaciones: Repositorio de Revistas UCR, DIALNET, Latindex, REDALYC Directorio y recolector de recursos digitales del Ministerio de Cultura de España, Directory of Open Access Journals. Diálogos Revista Electrónica de Historia ISSN 1409- 469X. Número especial 2008. Dirección web: http://historia.fcs.ucr.ac.cr/dialogos.htm

\title{
Oficios de representación en el concejo de Madrid durante el reinado de Fernando VI: el procurador general.
}

\author{
Manuel Salamanca López
}

e-mail: msalaman@ghis.ucm.es Universidad Complutense de Madrid 


\section{Formación y extracción social de los aspirantes.}

Una vez iniciado el proceso de selección, los diferentes candidatos elevaban al Concejo una petición, en la que defendían la idoneidad de sus personas y curriculum de acuerdo al perfil de la plaza a la que optaban, llegando incluso, en ocasiones, a adjuntar una relación de méritos a la súplica.

Los pretendientes pueden clasificarse en dos grandes grupos conforme a su categoría, experiencia y formación profesional, a saber, los que provienen del campo de la jurisprudencia (mayormente abogados de los Reales Consejos) o los que desempeñan cargos dentro del Concejo (regidores, asesores de corregidor y mayordomos de propios).

Respecto al primero encontramos personajes como Ignacio de Santa Clara y Villota, asesor de corregidor; Rafael Manuel Delgado, decano del Real Colegio de Abogados; Francisco Suárez de Rivera, que " a 23 años sigue en los tribunales el curso de varios negocios proprios y agenos... Que por las especiales noticias que tiene de las sisas desde su imposición puso en manos del rey dos dilatadas representaciones suyas en defensa de dichas rentas y de la jurisdición de V.I. y del Consejo contra las dos juntas de ellas que se formaron quitando a V.I. la administración y... logró extinguirlas y que se restituyese a V.I. el manejo...”1, y Francisco Arias y Camisón, quien presentó su curriculum por extenso a lo largo de varios folios, destacando sus problemas con la justicia $^{2}$-aunque salió airoso de todos los procesos en los que se vio implicado-, y su dilatada

$1 \quad$ Archivo de Villa de Madrid (en adelante A.V.M.), Secretaría, 2-399-14.

2 "Consta, assimismo, por diferentes certificaciones que de orden de su magestad en 6 de diciembre de 1725 por don Juan del Castillo, alcalde que era de Casa y Corte, se hicieron autos contra dicho don Francisco Arias y Camisón, don Juan Antonio de Ahumada y consortes sobre que declarassen qué oficial de la Secretaría del Despacho de Indias o de la provincia de ellas havía entregado a los referidos o a don Miguel Ventura Gallo, prevendado de la Santa Iglesia de la ciudad de México, la consulta o copia de la hecha a Su Magestad por el Consejo de ellas en 20 de diciembre de 1724 contra don Juan Manuel de Olivan, oidor y governador que era en dicha ciudad de la Sala del Crimen, a instancia de 240 montañeses vecinos de ella que le acusaban haver votado en desprecio de la nación montañesa y española e inducido a lo mismo a los alcaldes del crimen de la referida audiencia condenando a 3 ladrones que decían ser naturales de las montañas de Burgos a devengar en un obrage el importe del hurto que hicieron a un vecino de dicha ciudad, la qual consulta estando pendiente en manos de Su Magestad y sin resolver la insertó el referido Ahumada en un memorial que dio a Su Magestad en nombre del citado Olivan, de quien era apoderado con el referido don Miguel Gallo, en el qual satisfacía la referida acusación. Y que en 2 de enero de 1726 se le puso preso a dicho don Francisco Arias por testigo de apremio para que declarasse que oficial dio dicha consulta en una torre de la cárcel de corte donde estuvo encerrado y sin comunicación de persona alguna 7 meses y 24 días los 4 meses con dos pares de grillos hasta que en 24 de agosto del mismo año se le intimó real resolución de Su Magestad en que mandó que a costa de dicho don Francisco y por tres ministros fuesse llevado por 8 años al castillo de Pamplona y cumplidos no entrasse en 


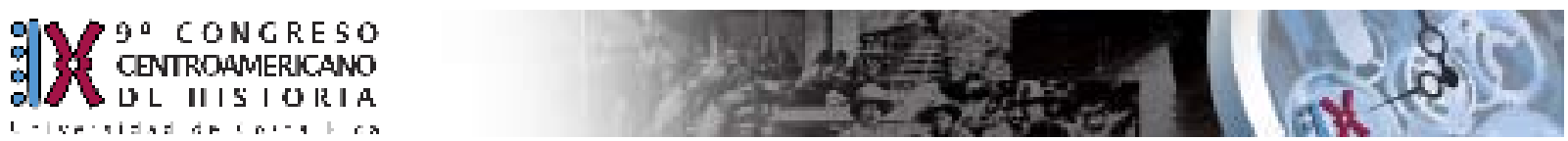

Indexaciones: Repositorio de Revistas UCR, DIALNET, Latindex, REDALYC Directorio y recolector de recursos digitales del Ministerio de Cultura de España, Directory of Open Access Journals. Diálogos Revista Electrónica de Historia ISSN 1409-469X. Número especial 2008. Dirección web: http://historia.fcs.ucr.ac.cr/dialogos.htm

\section{carrera profesional:}

“Consta se aprobó de abogado de los Reales Consejos en 12 de agosto del año passado de 1713 y que en virtud de título de su magestad de 16 de mayo de dicho año entró a servir una relatoría de la Sala de Alcaldes de Casa y Corte hasta 26 de junio de 1715 que quedó reformado y vacado una de las dos relatorías del crimen de dicha Sala en el año de 1716 y puéstose edictos a ella entre otros leyó

esta Corte sin licencia de Su Magestad ni quebrantase dicha orden, pena de doblados en uno de los presidios de África y en privación perpetua de hablar en negocios de Indias, pena de otros 10 años de presidio en África y de dos mil pesos aplicados a Su Magestad, y, assimismo, se le condenó en otros mil pesos de multa aplicados a Su Magestad en su Thesorería Mayor y en parte de costas y con efecto en 31 del mismo mes entregó dichos un mil pesos en la Thesorería Mayor y pagó 3.467 reales y medio por razón de costas y en 17 de septiembre del mismo año fue entregado el referido don Francisco Arias en dicho castillo por los expressados ministros, donde estuvo hasta 24 de marzo de 1727 que la piedad de Su Magestad le mandó salir de él y que no entrasse en esta Corte ni en 20 leguas de ella sin su licencia, la que, más bien informado Su Magestad, se sirvió de concederle por real decreto de 29 de abril de 1728 y con el motivo de que el Conde de Santistevan nombró al referido don Antonio de la Portilla para que sirviesse interin el impedimento de dicho don Francisco Arias, y haver este passado a relator del de Castilla bolvió a nombrar por interino del expressado don Francisco Arias y durante su ausencia al licenciado don Roque Iniesta, relator que era de la Chancillería de Granada hasta que en 10 de julio de 1727 en vista de que las referidas condenaciones no le permitian a dicho Don Francisco Arias exercer la expressada relatoría hizo consulta a Su Magestad para que se proveyesse, con la qual se conformó Su Magestad y se confirió al referido don Roque Iniesta en 17 de noviembre de 1727. Y haviendo instado el expressado don Francisco Arias a que la piedad de Su Magestad mandasse reveer la dicha causa de su prisión y le declarasse no haver sido reo en ella en 6 de mayo de 1737 se sirvió de expedir sus reales decretos...le declaró estar en su gracia no haver sido reo en dicha causa y por libre de todas las referidas penas y prohibiciones mandando se le tenga presente en las plazas y empleos que se proporcionassen a sus méritos...Y también consta por certificaciones de don Joseph Antonio de Yarza, secretario de Su Magestad y su escribano de Cámara más antiguo y de govierno del Consejo, $y$ de don Ignacio Igareda, su secretario, y escribano de Cámara en él, sus fechas 15 de enero de 1750 y 8 de julio del presente de 1754 y que de dichos capitulos conoció el señor don Francisco Joseph Zepeda del Consejo de Su Magestad en el de Castilla y dio su sentencia que se publicó en el Consejo en 2 de septiembre del año passado de 1745 de la que apeló por las partes y oidas consta por la dada por el referido señor don Francisco Zepeda y por el Consejo en 4 de agosto de 1749 que dicho día se consultó y se publicó en 8 de enero de 1750...Yde ella consta que al referido don Francisco Arias se le absolvió y dio por libres de los capítulos y cargos de que fue acusado declarando no haver cometido excesso alguno en el tiempo que sirvió dichos corregimientos y en su consequencia se condenó al referido capitulante en todas las costas processales causadas en dicha capitulación y, assimismo, a que le diesse al referido don Francisco Arias $6 . .000$ ducados por razón de los daños y pérdidas que havía padecido en la referida capitulación y por lo que en el cargo 17 declaró Francisco Zedrún, escribano real, y del número de ronda contra dicho Don Francisco Arias se le condenó a dicho escribano en 200 ducados para la real cámara y gastos de justicia y en 4 años de suspensión de oficio...Y, assimismo, consta que Su Magestad a consulta de el Consejo de 4 de mayo de 1750 concedió licencia para suplicar de la expressada sentencia a los referidos capitulantes Francisco Quiñones y consortes condenados y multados en ella y que no haviéndola mejorado se adhirió a ella el referido don Francisco Arias y pidiose confirmasse la citada sentencia aumentando a los capitulares y demás reos las condenaciones y penas. Y que con palabras expressas se le declarasse por buen ministro....”. A.V.M., Secretaría, 2-399-16. 
en el día que le fue señalado y por dicha Sala se propusieron tres al marqués de Mirabal, Governador del Consejo, para su nombramiento y le hizo en el referido Don Francisco para que sirviesse sin otro título que el citado de 16 de mayo de 1713; y en su virtud en 3 de junio de 1716 fue admitido y continuó sirviendo hasta 20 de noviembre del año passado de 1719, y ambas relatorías las sirvió sin sueldo alguno hasta que en el concurso que se hizo en el Real Consejo de las órdenes para la sobstitución de relator de la orden de Santiago por la indisposición del licenciado don Juan Montero relator propietario fue uno el referido Don Francisco... Y haviendo leído todos los opositores fue nombrado para servir la expresada sobstitución... Que puestos edictos a las ausencias y enfermedades de licenciado Don Gregorio Gavilanes, relator del Consejo de las Órdenes, por lo tocante a la de Santiago con ascenso a la propiedad de la relatoría de las de Calatrava y Alcántara se opuso y leyó con otros opositores el día 15 de febrero del año passado de 1716 con puntos de 24 horas y general aprobación; y también sirvió otro relatoría del propio Consejo de Órdenes por enfermedad del licenciado Don Juan Montero, relator de él, desde 25 de noviembre de 1715 hasta 15 de febrero de 716. Estudió en la Universidad de Salamanca...se graduó de bachiller en cánones...Y que haviendo escogido la referida de Alcántara se le despachó título de cavallero de ella en 20 de mayo de 1739 y le tomó en 22 de junio de dicho año y que professó a 15 de agosto de 1740. Assimismo, consta que por decreto de 17 de septiembre de 1741 fue Su Magestad servido nombrarle al expresado don Francisco Arias y Camisón por corregidor de las ciudades de Ronda y Marbella de que se le despachó título en 26 del mismo mes y año del que tomó la possessión en 17 de enero de 1742 ”3.

En cuanto al segundo, más numeroso, se compondrá de regidores, v.gr.: Juan de Bilbao y Agüero, Agustín Gómez Lozano, Manuel de Alcedo, Blas Ruiz Bayllo, Agustín Moreno de Prats y Sabasona, José Antonio de Pinedo, Mateo José de Larrea -secretario del rey-, y José Gómez de Pedrosa, "del Consejo de S.M. y su alguacil mayor del de Guerra...capitular más de doze años, hallándose con este motivo ynstruido en las dependencias del Ayuntamiento por aver entendido en la maior parte de ellas con la ocasión de las comisiones y juntas que estubieron a su cargo

3 A.V.M., Secretaría, 2-399-16. 
y expecialmente la de los repesos, reglamento general del estado eclesiástico, recuperación de tierras y propiedades de propios, pleitos y transaciones, reglamento del ministerio subalterno de justicia de orden de S.M. en la posada del señor don Pedro Colón de Larreategui con diferentes señores del Consejo y en la intervención de la quiebra de la thesorería de carnicerías y en cada una de estas juntas y comisiones averse ocupado más de quatro años..." "), asesores de corregidor (Ignacio de Santa Clara y Villota) y mayordomos de propios (Eusebio de Sabugal y Cepeda).

Finalmente, quedan por citar una serie de candidatos de difícil adscripción dado lo variopinto de su perfil ocupacional, v.gr:: Fernando Antonio de Salcedo y Tapia, gentilhombre de boca de Felipe V, paje de Carlos II y corregidor de las ciudades de Úbeda y Baeza. Antonio Gaspar de Pinedo, quien optó por dos veces al cargo. La primera con motivo del fallecimiento de Francisco Carlos Pérez de Villaloz, aunque el Concejo se decantó en esta ocasión por la figura de Juan de Bilbao y Agüero, quizás por lo vago de los argumentos y curriculum de Antonio Gaspar a la hora de hacer valer su propuesta, pues "dice que aunque no tiene mérito alguno en serbicio de V.S.I. se halla con vivos deseos de sacrificar en él su obedicencia... "’. Más suerte tuvo en el segundo intento, al suceder en la procuraduría al referido Juan de Bilbao, esta vez en calidad de regidor de la villa de Madrid. Por último, sólo queda hacer referencia a la solicitud de Sancho Sáenz de Erquíniigo, que basó la defensa de su candidatura en recordar los méritos de su padre, Antonio Sáenz de Erquínigo; no obstante, según se ha visto en capítulo aparte, el citado Sancho fue regalado más adelante con el título de regidor.

En el terreno relativo a la extracción social de los aspirantes, resulta llamativo -siempre teniendo en cuenta que era requisito imprescindible el pertenecer al estamento nobiliario (" $\mathrm{El}$ lizenciado don Ignacio de Santa Clara y Villota...expone con su mayor respeto que se halla recivido en el estado de hijosdalgo de esta coronada villa de Madrid desde el día 16 de octubre de 1744")-, que un número considerable de ellos fueran caballeros de alguna orden militar, v.gr.: Santiago: Juan de Bilbao y Agüero7, esposo de Margarita Mariana Álvarez Bustamante

$4 \quad$ A.V.M., Secretaría, 2-399-14.

5 A.V.M., Secretaría, 2-399-14.

6 A.V.M., Secretaría, 2-399-16.

7 A.H.N., Órdenes. Santiago, leg. 59, expedientillo núm. 5.939 (septiembre, 1697). A.H.N., Órdenes.

Santiago, Datas, leg. 198, núm. 16.478 (año 1697). ARCHIVO HISTÓRICO NACIONAL, Sección de Órdenes Militares. Índice de expedientillos y datas de hábito de caballeros de Santiago, Calatrava, Alcántara y Montesa, Madrid: Ministerio de Educación y Ciencia, 1976, pp. 78 y 628. 
Esquivel y Arce (a.1723) ${ }^{8}$, Fernando Antonio de Salcedo y Tapia ${ }^{9}$, Mateo José de Larrea ${ }^{10}$, José Antonio de Pinedo ${ }^{11}$. Alcántara: Sancho Sáenz de Erquínigo ${ }^{12}$ y Francisco Arias y Camisón ${ }^{13}$.

Al respecto, resultan interesantes las palabras de Ana Guerrero Mayllo, para quien el procurador general

"era elegido entre candidatos pertenecientes al estado de caballeros hijosdalgo de Madrid. Quizá esto justifique la frecuencia con que se produce la negativa de los designados a ocupar el cargo" ${ }^{14}$.

Situación, según parece, del todo distinta a mediados del XVIII, dada la alta cifra de solicitudes que se presentaron en cada convocatoria.

Al hilo de lo hasta ahora dicho y continuando con el magisterio de la citada Ana Guerrero, destaca que el único impedimento para ocupar la plaza de procurador general de Madrid radicase en la imposibilidad de tener lazos de parentesco con algún capitular, traba surgida a partir de 1587, pues también en este aspecto el panorama será diferente. De este modo, el referido Antonio Gaspar no sólo llegó a desempeñar a lo largo de su vida dos regidurías distintas, sino que, además, al momento de su elección como procurador, su sobrino, José Antonio Pinedo ${ }^{15}$, tenía

8 Padres: Jerónimo Álvarez de Bustamante y María Ventura de Esquivel. Abuelos paternos: José Álvarez de Bustamente y Ana González. Abuelos maternos: Francisco Félix de Esquivel y Margarita de Arce. María Ángeles PÉREZ CASTAÑEDA y María Dolores COUTO DE LEÓN, Pruebas para contraer matrimonio de las órdenes de Calatrava, Alcántara y Montesa, Madrid: Dirección General del Patrimonio Artístico, Archivos y Museos. Subdirección General de Archivos, 1980, pp.16-17.

9 A.H.N., Órdenes. Santiago, Datas, leg. 199, núm. 16.946 (año 1711). ARCHIVO HISTÓRICO NACIONAL, Sección de Órdenes Militares. Índice de expedientillos..., p. 724.

10 A.H.N., Órdenes. Santiago, leg. 78, expedientillo 7.586 (marzo, 1753). ARCHIVO HISTÓRICO NACIONAL, Sección de Órdenes Militares. Índice de expedientillos..., p. 295.

11 A.H.N., Órdenes. Santiago, expedientillo núm. 6.938 (noviembre, 1729), A.H.N., Órdenes. Santiago, Datas, leg. 199, núm. 17.039. ARCHIVO HISTÓRICO NACIONAL, Sección de Órdenes Militares. Índice de expedientillos..., pp. 334 y 710. A.H.N., Órdenes. Santiago, pruebas de ingreso (año 1730), sign. 6.492. Vicente de CADENAS Y VICENT, Caballeros de la orden de Santiago. Siglo XVIII, Madrid, 1977, vol. II, pp. 306-308. 12 A.H.N., Órdenes. Alcántara, expedientillo núm. 14.473 (mayo, 1716). ARCHIVO HISTÓRICO NACIONAL, Sección de Órdenes Militares. Índice de expedientillos..., p. 486.

13 A.H.N., Órdenes. Alcántara, expedientillo núm. 14.519 (octubre, 1738). ARCHIVO HISTÓRICO NACIONAL, Sección de Órdenes Militares. Índice de expedientillos..., p. 44.

14 Ana GUERRERO MAYLLO, El gobierno municipal de Madrid (1560-1606), Madrid: Instituto de Estudios Madrileños, 1993, p. 51.

15 Se le expidió título de regidor el 27 de marzo de 1733, cesando en el cargo durante el año 1756, al suceder a su tío al frente de la procuraduría general de Madrid. A.V.M., Secretaría, 2-288-66 y 2-399-16. 
voz y voto en el consistorio madrileño.

Por otro lado, los expedientes también contienen información referente a distintos familiares de los candidatos, que incluían los propios aspirantes con el objetivo de incrementar sus opciones de cara a la elección final. Todos estos datos nos retratan una panorámica, en ocasiones de lo más completa, de la extracción social de ascendientes y parientes. Así, por ejemplo, sabemos que Pedro de Bilbao y Agüero, hermano de Juan, desempeñó el oficio de regidor a lo largo de más de ocho años; que Antonio Sáenz de Erquíñigo, padre de Sancho, ejerció el oficio de regidor, llegando a ser decano de Madrid, o que Antonio Gaspar de Pinedo ocupó las plazas de regidor y procurador general Madrid, de igual manera que su sobrino, José Antonio de Pinedo. En la misma línea, Fernando Antonio de Salcedo argumentará que "es hijo único de don Francisco Antonio de Salcedo y Tapia, capitular que fue de V.S. y nieto de don Juan Cuero de Tapia, que también lo fue muchos años y más de quarenta decano del Ayuntamiento, procurador de Cortes, capitán de milicias, cuyos empleos sirvieron también don Gregorio de Tapia, su hermano, que murio secretario de Estado más antiguo del señor rey don Phelipe quarto y su hijo don Gregorio de Tapia, cavallero, procurador general y fiscal de la orden de Santiago"16.

Por último, resultan significativos, en razón a la profusión y minuciosidad de la información que aportan, los casos de Francisco Arias de Camisón ${ }^{17}$ y de Ignacio de Santa Clara

$16 \quad$ A.V.M., Secretaría, 2-399-14.

17 "También consta por certificación de los servicios del comissario general de la cavallería de los exércitos de Su Magestad don Alonso Fernando Arias y Camisón dada por don Pedro de Astorga, oficial de la Secretaría de Guerra, en 18 de noviembre de 1715 que dicho don Francisco Arias es hijo legítimo y heredero de don Juan Antonio Arias y Camisón que lo fue del citado comissario general y certifica consta por fees de oficios que dicho don Alonso Fernando Arias sirvió en los exércitos de Milán, Flandes, Cathaluña y Ciudad Rodrigo con diferentes plazas y empleos 47 años y 36 días desde 1 de octubre de 1610 hasta 1 de marzo de 1657 que murió en Barcelona de enfermedad los 5 años, 10 meses y 9 días primeros en el exército de Milán con plaza de aventajado y page de gineta en los tercios de don Rodrigo Quiroga y don Rodrigo de Lerma en cuyo tiempo passó de theniente a la compañia de cavallos corazas de don Fernando de la Carrera para passar a Flandes en la que sirvió con dicho grado y en el regimiento del Conde de Fonclara hasta 13 de octubre de 1641 que se le nombró capitán de cavallos y formó la compañía de ramos de otras para venir a España en virtud de patente del señor infante cardenal y por real títuló de 16 de abril de 1644 le nombró Su Magestad comissario general de la cavallería del exército de Ciudad Rodrigo con 150 escudos de sueldo al mes en atención a sus especiales méritos y repetidas heridas que recibió en Italia y Flandes y mandó sirviesse de tal comissario general con compañía lo que executó hasta 15 de junio de 1645 que con dichos empleos se le mandó passar a servir a dicho don Alonso de aventajado y page de gineta y theniente en el palatinado y guerra con el sueco y que se halló en todas las ocasiones de ella y que en Habilisten le mandó dicho general Sylva passasse el Rhin con una partida a tomar lengua y bolvió con algunos prisioneros y que la noche que el Rey de Suecia passó el Rhin lo vio pelear con mucho valor y recibir una herida de pica en la cabeza y que se halló en los Sitios y Tomás de Yliberg y Espira y que le embió con algunos cavallos a empezar la escaramuza con el enemigo y quando este atacó la vanguardia de 


\section{II) \\ ix \\ d)}

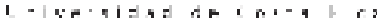

Indexaciones: Repositorio de Revistas UCR, DIALNET, Latindex, REDALYC Directorio y recolector de recursos digitales del Ministerio de Cultura de España, Directory of Open Access Journals.

Diálogos Revista Electrónica de Historia ISSN 1409-469X. Número especial 2008. Dirección web: http://historia.fcs.ucr.ac.cr/dialogos.htm

\section{y Villota, ejemplo este último a quien pertenece el extracto del curriculum que se presenta a continuación:}

nuestra cavallería y fue dicho don Alonso uno de los que más se señalaron haciendo mucho daño al enemigo lo que en aquella conyuntura y estado fue servicio digno de que Su Magestad se le remunerasse y que el día primero del año de 1632 le embió a tomar lengua cerca de Bormes con treinta cavallos y descubrió cinco batallones enemigos que aguardaban saliesse nuestra gente de Francandal para cortarla y escaramuceo con ellos con mucho valor y le siguieron hasta las murallas de dicha plaza que salió a socorrerle el marqués de Mortara y que se halló en toda la campaña de Mastrik y siempre desempeño las obligaciones de honrado cavalleo y valeroso soldado. Que el capitán general don Fernando MIguel de Tejada certifica le vio servir en Milán, Flandes y España con dichos empleos y vio se halló quando los enemigos fueron a ganar la media luna y puente de Cariñán donde recibió trece heridas y fue prisionero yque en la batalla que se presentó a los franceses que fueron a socorrer la ciudadela del Casal del Monferrato defendió su puesto y vio que passó a Flandes y al Palatinado y al socorro de Mastrik y que repetidas veces fue a tomar lengua y se hallo en la batalla de la Campiña junto a Vox y en el Reencuentro junto a Namur y socorro de Lobayna y quando el enemigo fue a ganar a Bruselas y se fue a tomar la Isla de Estevan Berto fue uno de los que voluntariamente se ofrecieron a passar a nado el Mousa y que en el Reencuentro de aquel día se señaló mucho y en las recuperaciones de Argento, Fuerte de Lobayna, Diste y Ostral y fortificar el Fuerte de Gonel y se halló en el socorro de Perpiñán y a ganar la Castellanía, Socorro de Mora, y Esguazo del Segre en que se derrotó al enemigo en las horcas de Lérida. Y que en el exército de Ciudad-Rodrigo a 18 de agosto de 1644 fue con la cavallería a buscar al rebelde a Almeyda y le derroto con muerte del comissario general de ellos tres capitanes de Cavallos y otros oficiales con 46 prisioneros y en 6 de octubre del mismo hizo otra entrada y peleo y derrotó a los enemigos y en otras assistió con mucha puntualidad y valor. Y que los thenientes generales de la cavallería don Juan Pérez de Vivero y marqués de Montafia certifican vieron que en Flandes se halló en todas las ocasiones que huvo y en la entrada en Picardía, Sitios, y Tomás de la Capela, Xatelete, Buain y Colbie, Passage de Soma y Reencuentros con los franceses y que en el Socorro de Santome con 100 cavallos y 100 mosqueteros ocupó el passage de los Enemigos por un bosque y fue diferentes veces a reconocer el campo del enemigo y que se halló en la Toma del Comboy que passaba al Casal y en las riveras de Génova se halló en la Toma de Puerto-Mauricio, Omilla y Veintemilla y Sitios de Berceli y Casal. Y en el Reencuentro junto a San Badi donde se derrotó al enemigo y recibió tres heridas de pica y que en el puente de Cariñán quedó muy mal herido y prisionero. Y el general don Fr. Juan de Palabesino certifica le vio servir en los sitios que se pusieron sobre Barcelona en el quartel de Sanz. Y que quando el enemigo atacó a San Ferriol le mataron el cavallo en que estaba montado. Y quando el General la Mota atacó la iglesia del Sarrio e intentó ganar el fuerte de Santa Isabel fue atravesado de un mosquetazo y se halló quando el varón de Butier fue a quitar el vagaje y ganados a las murallas de Barcelona y fueron los franceses a romper la guardia de Casa Blanca y camino de San Badi. Y quando la restauración del Fuerte de San Juan de los Reyes fue atravesado de otro mosquetazo y la noche que el enemigo intentó socorrer la plaza por las líneas y el marqués de Mortara certifica passó con él a ganar la costa y al Palatinado y que en Francandal le nombrò para romper el cuerpo de Guardia del enemigo junto a Bormes y escaramuceo hasta que se le socorrió y traxo 4 prisioneros y quedó herido y se halló en la retirada que hizo el Conde de Dender a Treveris y el día que el Rengrave de Oto quiso estorvar el passage fue uno de los que empezaron la escaramuza para entretenerle hasta que nuestra gente passó el puente y después se señaló mucho en el reencuentro y en las tres últimas campañas, por cuyos méritos los referidos generales le juzgan muy digno de la real atención y que no consta en los papeles de dicha Secretaría de Guerra que por razón de dichos méritos se huviesse hecho gracia ni merced alguna al referido don Alonso Fernando Arias y Camisón ni a sus descendientes hasta el citado día 18 de noviembre de 1715 que el citado don Pedro Astorga dio la referida certificación arreglada a dichos papeles originales”. A.V.M., Secretaría, 2-399-16. 
"Que es hijo legítimo de don Joseph de Santa Clara y de Doña Josepha de Villota y del Hoyo, vecinos que fueron de la citada villa de Santander, sobrino de Don Joseph de Villota del Hoyo, que falleció inquisidor decano del Santo tribunal del reyno de Granada. Y, assimismo, de don Luis del Hoyo, ministro que fue del Consejo y de Don Carlos del Hoyo, inquisidor y canónigo, que fue de Toledo hermanos uno y otro de Doña Ana del Hoyo, su abuela materna. Que es hermano por afinidad de don Juan Martínez Matute, canónigo de la Santa Iglesia Cathedral de León y juez subdelegado de la Santa Cruzada en aquel obispado y del doctor don Manuel Martínez Matute, theólogo examinador de la nunciatura, capellán de honor de Su Magestad y cura de la villa de Aravaca y lugar de las Rozas de este arzobispado, quien como tal capellán de honor fue nombrado para ir como fue sirviendo de párroco, con especial aprobación de sus magestades, a la sereníssima señora doña María Theresa de Borbón, infanta de España, y Delphina de Francia y a su real comitiva en el viage de S.A. a aquel Reyno. Y ultimamente consta que haviendo pedido a la justicia y ayuntamiento de Madrid le diesse el estado que le corresponde y precedidas las diligencias judiciales con presentación de papeles de nobleza por sus dos líneas paterna y materna y demás que en tales casos se acostumbra se le admitió y recibió en el estado de cavalleros hijosdalgo en el día diez y seis de octubre de mil setecientos quarenta y quatro, como en todo lo referido más largamente consta y parece de títulos, certificaciones y otros papeles que a este fin ha presentado"18.

\section{Funciones y salarios.}

Según Jerónimo Castillo de Bobadilla

“Los procuradores generales de los estados ni los síndicos que assisten a los ayuntamientos, no podrán ser bastecedores, ni interessados en ello, y que incurrirán en las penas de la dicha ley, porque aunque es assí, que regularmente no tienen voto, ni voz en ellos para más que requerir y contradezir, (porque) sus oficios son, principalmente, ser veedores, fieles, censores, y procuradores del bien común (...)

A.V.M., Secretaría, 2-399-16. 


\title{
9. CONGRESO \\ d) CENTRDAMERICANO \\ d) 2 SL IIIS I O I I A
}

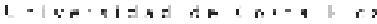

Indexaciones: Repositorio de Revistas UCR, DIALNET, Latindex, REDALYC Directorio y recolector de recursos digitales del Ministerio de Cultura de España, Directory of Open Access Journals. Diálogos Revista Electrónica de Historia ISSN 1409- 469X. Número especial 2008. Dirección web: http://historia.fcs.ucr.ac.cr/dialogos.htm

\begin{abstract}
porque ellos, si los regidores con sus ganados comen los pastos, ocupan los términos, defraudan los propios, usurpan los pósitos y si los oficiales públicos faltan y exceden de sus obligaciones, dan noticia a la justicia para que lo remedie, y tienen fuerças y poder en la República, como defensores della" ${ }^{\prime \prime}$.
\end{abstract}

En opinión de Jerónimo Castillo de Bobadilla la figura del procurador general debía encargarse de una serie de atribuciones de lo más genérico, como ser "veedores, fieles, censores y procuradores del bien común”20, tareas que, según Ana Guerrero Mayllo²1, con el paso del tiempo se redujeron a la mera representación ${ }^{22}$ de Madrid en sus pleitos ${ }^{23}$ ante el Consejo y la

19 Jerónimo CASTILLO DE BOBADILLA, Política para Corregidores y Señores de vasallos, en tiempo de paz y de guerra y para perlados en lo espiritual y temporal entre legos, juezes de comissión, regidores, abogados y otros oficiales públicos y de las iurisdiciones, preeminencias, residencias y salarios dellos y de lo tocante a las de órdenes y cavalleros dellas: tomo primero, Barcelona: por Gerónimo Margarit: a costa de Miguel Manescal, 1616, Lib. III, Cap. IV, 41.

20 Jerónimo CASTILLO DE BOBADILLA, Política para corregidores..., Lib. III, Cap. IV, 41.

21 Ana GUERRERO MAYLLO, El Gobierno Municipal..., p. 51.

22 "Acordose dar como se dio facultad a el señor don Joseph Antonio de Pinedo, cavallero del orden de Santiago, procurador general de Madrid, para que en su nombre pueda otorgar y otorgue a favor de los procuradores nombrados por este ayuntamiento poder general para la prosecución de todos los pleytos caudas y negocios tocantes a propios y demás expedientes de Madrid que se hallan pendientes y se movieren en adelante con calidad de que no puedan responder a demanda nueba que se ponga a esta villa hasta que notifique y haga notorio en este dicho ayuntamiento y para el entero efecto de lo que en la expresada razón obrare y executare se le da y confiere por Madrid amplio y expecial poder en bastante forma con todas las clausulas oligaciones requisitos renunciación de leyes y demás circunstancias que sean necesarias sin reservación de alguna que no se aya de entender omitida en este acuerdo del que se dará a dicho señor procuador general certificación que le sirva de poder en forma -Acuerdo. Madrid, 31 de enero de 1757-”. A.V.M., Secretaría, 1-264-2.

$23 \mathrm{Al}$ respecto resulta de interés la información siguiente:

"El cargo (si hay atraso en estas diligencias) es grande contra el Procurador General, pues en su viveza y gran representación consiste el éxito vreve de algunas, que siendo actor o reo Madrid no tiene combeniencia se dilaten. Siempre se ha mirado esto con particular cuidado, pues en el año de 1601 se despachó real provisión su fecha 4 de marzo de él para que hubiese en el Ayuntamiento una tabla dende se sentasen todos los pleytos pendientes de poca o mucha consideración siendo obligación del Procurador General dar cuenta en cada semana en el primero ayuntamiento que por cada vez que lo dejase de hacer se le quitasen 4.000 maravedís de su salario, para lo qual se pusiese por el escribano de Ayuntamiento en el libro el día que lo executase y la misma pena el escribano que dejase de sentar la noticia que el procurador general diese.

Vease la citada provisión que es digna de tenerse presente la qual ha pedimiento de Madrid se sacó copia sobrecartada en Valladolid en 13 de nobiembre de 1602.

Hase puesto siempre gran cuidado por Madrid en la solicitud de estas dependiencias y dado muchas y varias providencias para conseguir la vrevedad de su conclusión y en el año de 1608 solicitó y alcanzó de S.M. la gracia de que su Corregidor conociese de todos los pleytos y demandas que se supiesen siendo esta villa actora o rea y se mandó por cédula de 14 de junio del referido año de 1608 hiciese pago a todos los acreedores de lo que se les devía y debiese por Madrid conforme a las escripturas de créditos que tubiesen con inhivición 
Sala de Alcaldes de Casa y Corte, además de los contenciosos derivados de las cuentas que se tomaban a los mayordomos del pósito ${ }^{24}$. Al respecto resulta de interés el siguiente testimonio:

"El señor procurador general expresó en este ayuntamiento el orden en que seguía los expedientes y pleitos que Madrid tenía según y como lo havían hecho sus antecesores a fin de que el Ayuntamiento se sirviese ordenarle si lo havia de executar en otra comformidad o con comunicación de los cavalleros comisarios de pleitos por desear solo executar lo que fuese del agrado del Ayuntamiento, en cuya inteligencia se acordó que dicho señor procurador general continuase en el seguimiento de los pleitos y dependienzias de Madrid en la forma que lo executava

a los alcaldes de Corte y otros qualesquiera jueces y justicias de estos reynos y que los escribanos de probincia y otros qualesquiera en donde parasen los autos los entregasen originales al escribano que por el corregidor se nombrase.

A esta cédula se dio cumplimiento por el Consejo en Sala de Gobierno en 9 de septiembre de 1610 y lo repitió por otro auto de 31 de 1611 y por otro de 21 de agosto de 1617 donde se acudió por diferentes motivos. En 7 de marzo de 1629 despachó S.M. otra cédula conformando la antecedente y ampliándola no sólo para que el Corregidor procediese al pago de lo que la villa debiese sino para que perpetuamente procediese a la cobranza de lo que la debiesen con inhivición a todas las justicias en qualesquiera juicios y litigios de esta calidad en que fuese actora o rea en atención a haber concurrido en el servicio que el Reyno junto en Cortes hizo a S.M. en el referido año de 1648 de diez y ocho millones de ducados cargados sobre las sisas de vino, vinagre, aceyte y carnes y con la expresa condición de haber de tener esta gracia fuera de contrato rezíproco y obligatorio entre S.M. y la villa de Madrid.

Y por otra cédula despachada a favor de don Yñigo Fernández de Córdoba y Mendoza, Conde de Torralba, Corregidor de Madrid, su fecha 16 de octubre de 1648 mandó S.M. se guardase, cumpliesen y ejecutasen los antecedentes y que el Corregidor conociese de todos los pleytos egecutibos y ordinarios que sobre materia de maravedís deviese o se debiesen a la villa y que por los escribanos del número o probincia $u$ otros qualesquiera ante quien pasasen se entreguen al que por el Corregidor se nombrase, y en caso de no hacerlo se les apremiase por todo rigor de derecho por inhivir a todos y qualesquier jueces de este conocimiento quedando las apelaciones sólo al Consejo de Castilla en Sala de Gobierno y en 19 de octubre del referido año por el expresado señor Corregidor se dio cumplimiento habiendo la citada cédula presentado don Domingo de la Lastra, Procurador General de Madrid.

La vrevedad en el expediente de los pleytos es encargada en todas las leyes y especialmente en la 12, título 4, de las de la Partida, que dice: Acabamiento en fin deben dar derechamente los jueces a los pleytos que fuesen comenzados delante de ellos más hay una que pudieren, ca según dijeron los sabios antiguos ningún pleyto nin se pueda mucho alargar ante los juzgadores derechos o acuciosos. Y de la ley real en la Nueva Recopilación, título 17, libro 4, Bobadilla en su Política, $2^{a}$ parte, $n^{\circ} .78$, folio 393 y núm .87 y 88, folio 398”. A.V.M., Secretaría, 7-46-14 y 4-127-1. A.V.M., Manuscritos, libro 150, fols. 171 y 173.

24 Para más información, véase: Manuel SALAMANCA LÓPEZ, “"Razón de los más prinzipales pleitos y expedientes seguidos y promovidos" por el procurador general Antonio Gaspar de Pinedo (1747-1753): una fuente de carácter municipal para una historia social, económica y judicial de Madrid”, Documenta \& Instrumenta, 2 (2004), pp. 69-97. 
y practicava, y que en los casos que para la vista y determinación de alguno fuese comveniente que a nombre de Madrid se ablase y visitase a los ministros noticiase a los cavalleros comisarios de pleitos de ellos para que lo pudiesen hacer a nombre y representazión de Madrid”.

(Acuerdo. Madrid, 18 de abril de 1749)

Con todo, estas ocupaciones pronto desbordaron la capacidad de maniobra de dichos oficiales, que se vieron obligados a solicitar el concurso y ayuda de una serie de colaboradores (tenientes -figura que surgió desde 1584-, agentes, etc.), cuya labor se vería complementada con el trabajo realizado por los comisarios de pleitos y los abogados del número de Madrid. Al hilo de lo hasta ahora dicho tenemos constancia de que hasta el año 1715 existían en el concejo de Madrid dos plazas de agente, una de abogado supernumerario y otra de teniente de procurador, además de cuatro abogados del número y dos comisarios de pleitos. Sin embargo, este panorama cambiaría a partir de ese momento con motivo de la institución del reglamento de salarios de ese mismo año:

"Al theniente del señor procurador general limitarle el salario, suprimir un ajente y el abogado supernumerario de Madrid lo tiene por perjudizialismo, pues aun los quatro ministros siendo los tres que oi ay, por haver fallezido don Manuel de Cartajena, de tantas experienzias, aplicazión y zelo son incapazes de dar entero expediente con los quatro abogados que se dize que den a más de ziento y tantos pleitos que ai pendientes sin lo que nuevamente fomenta la industria o nezesidad; y asi le pareze comviene nombrar el quinto abogado y el terzer ajente sin moderar a los unos y a los otros los sueldos que gozavan pues si la constituzión del tiempo fuese más faborable y las sisas no tubiesen tanto decremento como manifiesta no estar satisfechos los interesados más que hasta el año de mill setezientos y nueve por lo general de las sissas y por lo del tavaco hasta el de setezientos y siete causandolo el menor valor y exsuberantes entregas de valimientos y servizios que importaran zerca de un mill y ochozientos quentos de maravedís no dudaría en augmentarles los 
gozes quando es razón clara que verdaderamente alienta a el travajo el acreeszerse el premio en la remunerazión”25.

No obstante, la realidad se torna más compleja sólo con echar un vistazo a la información contenida en los libros de actas. Tanto es así que resulta difícil encontrar una sola acta en la que no aparezca citado dicho cargo al frente de algún negocio del municipio, por muy dispares que parezcan los asuntos tratados. Sirvan de ejemplos los acuerdos siguientes:

"Viose una petición de Gregorio Alonso y Francisco Marín, repartidores del Gremio de mesoneros de esta villa, en que suplicaban a Madrid les conzeda postura para la venta de zebada y paja en sus mesones. Y se acordó ynformen los señores comisarios de repeso mayor y procurador general".

(Acuerdo. Madrid, 22 de agosto de 1746)

"Teniendo presente lo acordado por Madrid en dos de este mes sobre la obra que se nezesita hacer en el pretil de los Caños del Peral según la declaración de Joseph Álvarez, vista el citado día. Se acordó ynforme el señor procurador general”.

(Acuerdo. Madrid, 30 de octubre de 1747)

"Diose quenta de un memorial de Don Antonio Ocharán y Carranza acompañado de la provisión despachada a su fabor por el señor juez mayor de Vizcaya y de la auxiliatoria del Consejo para que en esta villa y demás del reyno se le tenga por cavallero hijodalgo y guardar las preheminencias que como tal le corresponden y pidiendo se mandase remitir al procurador xeneral para que con lo que ynformase se le admitiese al goce de los oficios onorificos que Madrid probehe. Y se acordó vealo el señor procurador xeneral quien ynformará lo que se le ofrezca".

(Acuerdo. Madrid, 18 de agosto de 1749) 
"El señor procurador general manifestó a este Ayuntamiento estarse siguiendo pleito entre la villa de Pinto y el lugar de jetafe sobre un despoblado y diferente porciones de tierra en que tenía interés los propios de esta villa.

$Y$ se acordó que dicho señor procurador general continue las diligencias en dicho pleito que los gastos que se causen se satisfagan por su theniente quien los ponga en la quenta de los demás correspondientes a los de esta Villa”.

(Acuerdo. Madrid, 10 de mayo de 1754)

"Viose un memorial de el excelentísimo señor Conde de Mazeda y Taboada en que exponía perteneze a S.E. unas casas cocheras azesorias a las principales que tambien posee en la calle y plazuela del Numpcio, en las que yntenta reedificar diferentes vibiendas para familia; y que, mediante pertenezer a los propios de esta Villa un sitio esconze de mala vista que embarazava la tirantez de las dos fachadas que ha de tener dicha vivienda, suplicava a Madrid que con vista de el plan que presentava se reconoziese el menzionado sitio y conzederle en permuta de otro que zede s.e. como demuestra el expresado plan. Y se acordó ymformen los cavalleros comisario de el quartel y procurador general".

(Acuerdo. Madrid, 5 de mayo de 1758)

Por todo esto, el oficio de procurador será uno de los más respetados dentro del Concejo. Asimismo, se convertirá, al contrario de lo acaecido en la etapa estudiada por Ana Guerrero Mayllo, en objeto de codicia por parte de numerosos funcionarios con aspiraciones de hacer carrera en la administración, o, por qué no, en un apetitoso bocado para aquellos con menos pretensiones o posibilidades. No en vano este cargo era uno de los mejor remunerados del Concejo, tan solo por detrás del corregidor (40.000 reales), escribano mayor propietario (25.000 
reales), contadores de cuentas (20.027 reales) y tesorero (20.000 reales). No obstante, el referido reglamento de 1715 vino a mermar los ingresos que cobraban con anterioridad a esta fecha, unos 20.456 reales anuales de salario, más otros 500 en concepto de aguinaldo navideño, dado que a partir de ese momento recibirán 13.000 reales de sueldo y una parte proporcional sobre un total de 1.746 reales destinado a los miembros del Concejo por Navidad. Sirvan de complemento a lo hasta ahora dicho las siguientes palabras:

“En quanto al señor procurador general es zierto que hasta el año de mill setezientos y ocho solo gozó el salario que consta de la zertificazión de la contaduría de quentas y después se sirvió el Consejo sin acuerdo de Madrid señalarle quinientos ducados en cada un año por razón de la asistenzia que devía tener a las arcas, haviéndose introduzido tanbién el darle la propina en sus comisiones que a los capitulares que antes de dicho año no se davan, porque su ofizio es el asistir en qualquier junta y caso que se ofrezca del servizio del público, lo qual se tubo presente para la asignazión del salario y gozes que tubo hasta dicho tiempo. Y mediante el travajo preziso que deve tener y se considera en la defensa de todos los pleitos de Madrid y del público y asistir al consejo a la vista de ellos se le deve areglar su goze a lo que lexitimamente fuere justo"26.

Con todo, en ocasiones, estas sumas podían verse incrementadas con otros ingresos, aunque no llegaban a beneficiarse directamente de ellos:

"Líbrense al señor don Antonio Gaspar de Pinedo, procurador general desta Villa como poder haviente de don Juan Pio de Montufar, Marqués de Selba Alegre, patrono de las memorias que fundó don Francisco Enrriquez de Villacorta, los 11.812 maravedís vellón de renta al año y por todo el próximo pasado de 1751 que deve haver por el censo que a dicho patronato pertenece contra los propios de esta villa”.

(Acuerdo. Madrid, 12 de enero de 1752)

26 A.V.M., Secretaría, 2-311-5. 
A las cantidades anteriormente reseñadas debemos añadir otro tipo de gratificaciones de las que se beneficiaban, como por ejemplo cera, a razón de una libra con motivo de las procesiones de san Antonio Abad, san Ildefonso y san Sebastián, o la que se repartía por la festividad del Corpus Christi. Asimismo, al igual que sucedía con los corregidores y capitulares, también podían recibir bulas:

"El señor secretario don Phelipe López de la Huerta hizo presente que en consequencia de lo resuelto por S.M por real orden de 12 de este mes para que en cada un año se diesen al señor correxidor 12 bullas de vivos y dos de ylustres a cada uno de los 40 capitulares 6 de vivos y una de ylustres igual número al señor procurador general y el mismo a cada uno de los dos secretarios de Ayuntamiento por su concurrencia al acto de la procesión y predicación de la Santa Bulla se avía por el señor comisario general de la Santa Cruzada despachado a su favor el correspondiente libramiento para la entrega de 270 bullas de vivos de tasa ordinarias y 45 de illustres..."

(Acuerdo. Madrid, 22 de diciembre de 1755)

Por último, los procuradores del mismo modo al resto de miembros del Ayuntamiento participaban de ciertas prerrogativas, centradas en la mayoría de los casos en la asistencia a actos públicos, como procesiones, rogativas, etc.:

“En este ayuntamiento se asignó la forma en que se han de repartir las varas del palio entre los cavalleros capitulares, procurador general y secretarios que le han de llevar en la procesión del próximo día del Corpus, a cuyo fin se les darán los avisos correspondientes en la forma acostumbrada”.

(Acuerdo. Madrid, 2 de junio de 1749) 